This is a self-archived - parallel published version of this article in the publication archive of the University of Vaasa. It might differ from the original.

\title{
Autonomous soft open point control for active distribution network voltage level management
}

Author(s): Hafezi, Hossein; Laaksonen, Hannu

Title: Autonomous soft open point control for active distribution network voltage level management

Year: $\quad 2019$

Version: Accepted manuscript

Copyright C)2019 IEEE. Personal use of this material is permitted. Permission from IEEE must be obtained for all other uses, in any current or future media, including reprinting/republishing this material for advertising or promotional purposes, creating new collective works, for resale or redistribution to servers or lists, or reuse of any copyrighted component of this work in other works.

\section{Please cite the original version:}

Hafezi, H., \& Laaksonen, H. (2019). Autonomous soft open point control for active distribution network voltage level management. In: 2019 IEEE Milan PowerTech, Milan, Italy. Institute of Electrical and Electronics Engineers (IEEE). https://doi.org/10.1109/PTC.2019.8810735 


\title{
Autonomous Soft Open Point Control for Active Distribution Network Voltage Level Management
}

\author{
Hossein Hafezi, Hannu Laaksonen \\ School of Technology and Innovations, Electrical Engineering \\ University of Vaasa \\ Vaasa, Finland \\ hossein.hafezi@univaasa.fi
}

\begin{abstract}
With rapid development towards sustainable smart grids, the future electricity distribution networks should be able to host more and more distributed generation (DG) and enable also higher demand peaks e.g. due to charging of electric vehicles (EVs). Soft Open Point (SOP) is one potential enabling solution, which could provide multiple functionalities for future active network management (ANM) and improve resiliency and flexibility of future electricity distribution networks. The focus in this paper is to design a new control method for SOP inverters in back-to-back (B2B) configuration. This paper proposes an outer autonomous reactive power controller for active voltage level management in an example medium-voltage (MV) distribution network. The developed new SOP control methods are validated with Matlab based simulation results. Results show that developed autonomous SOP control is an effective option for active voltage management in future MV networks.
\end{abstract}

Index Terms-Smart Grid, Soft Open Point (SOP), Volt/VAr control, Droop control.

\section{INTRODUCTION}

Integration of distributed generation (DG) in medium and low-voltage (MV and LV) distribution networks has been rapidly growing for many years. Connection of large amount of DG units in the distribution networks has many different effects. Standards define grid code and installation requirements which limit the DG units hosting capacity of network [1]. Moreover, the EU targets and requirement for more Renewable Energy Sources (RESs), increase the need for more DG hosting capacity in distribution networks. In addition, due to increasing dependency on electricity it is important to increase the electricity supply quality and reliability by reducing e.g. the number of supply interruptions. In this regard and with rapid development towards smart grids, the future distribution networks should be able to host more and more DG and enable also e.g. charging large amount of electric vehicles (EVs) [2].

The intermittent nature of renewables based DG units, like photovoltaic (PV) and wind power, can cause voltage fluctuations on distribution network due to rapidly changing active power output of the units. With high penetration of PV and wind, it can be that the distribution network cannot serve all customer load in different situations without active control of flexible, distributed energy resources i.e. flexibilities. Flexibilities can consist of active $(P)$ and reactive $(Q)$ power control of flexible resources like controllable DG units, energy storages (ESs), controllable loads and EVs which are connected in MV and LV distribution networks. Potentially these distribution network connected flexibilities can provide different local (distribution network) and system-wide (transmission network) technical/ancillary flexibility services [3]. One system-wide flexibility option are also AC or DC interconnections between different transmission networks and countries. However, regarding distribution networks, traditionally many distribution networks have been operated by distribution system operators (DSOs) radially with normally open points (NOP). In the future, due to increased active network management, flexibility and reliability requirements, also at the distribution network level meshed or ring operation may need to be increased by closing the NOPs.

In general, rapid development of power electronics has opened up new utilization possibilities for them in smart grids [4]-[6]. Different solutions have also been proposed for voltage control and voltage level and balance management. STATCOM [7], Dynamic Voltage Conditioner (DVC) [8] and Open Unified Power Quality Conditioner (Open UPQC) [9] are among promising solutions. Soft Open Point (SOP) is another attractive power electronic based solution which can perform several functions in this context [4], [10]. SOPs are an interesting alternative to be replaced with NOPs in future smart grid systems [11]. SOPs can increase system flexibility adding several new feature and control possibilities. DSOs can combine benefits of radial and loop (mesh) network by installing SOPs at certain points of their distribution network [12], [13]. In the literature also other names than SOP has been used from this device such as for example; "SIPLINK" [14], "DC-link" [15], "SNOP" [16] and Loop Balance Controller (LBC) [17]. However, SOP is chosen to be used in this paper. In literature SOP has been introduced and analyzed in [10]-[12]. Authors in [13] proposed to include a storage 
system at SOP DC bus which can increase active power flexibility of it. Although two back-to-back (B2B) configuration is preferred in most applications, three leg DC link configuration has been also proposed and its performance is investigated in [14]. Despite all these developments, the control strategies for SOP are not studied in detail and research is ongoing. The focus in this paper is to design a new control method for SOP inverters in B2B configuration. This paper proposes an outer autonomous reactive power controller for active voltage level management in an example MV distribution network. The developed new SOP control methods are validated with Matlab based simulation results. Results show that developed autonomous SOP control is an effective option for active voltage management in future MV networks.

In the following, the Section II presents SOP hardware structure and its operation principle. Detailed SOP inverters controller and outer autonomous Volt/Var droop scheme is addressed in Section III. Simulation study results are shown in section IV followed by conclusion remarks in section $\mathrm{V}$.

\section{SOFT OPEN POINT SYSTEM AND PRINCIPLES}

Although SOPs have been studied in different configurations but the widely used configuration is two backto-back (B2B) inverters with common DC bus capacitor. Through this study, this $\mathrm{B} 2 \mathrm{~B}$ configuration has been considered.

\section{A. VSC B2B configuration}

Fig. 1 shows B2B configuration of SOP in an example radial distribution network. As it mentioned earlier, the device can be installed (replaced) at any NOPs of a distribution network. With this configuration, the reactive power of each inverters can be controlled independently from each other, as far as the nominal power (VA) of the inverter is respected.

However, the active power control can be unidirectional, in either directions, which means in Fig. 1 the active power balance of (1) should be respected always.

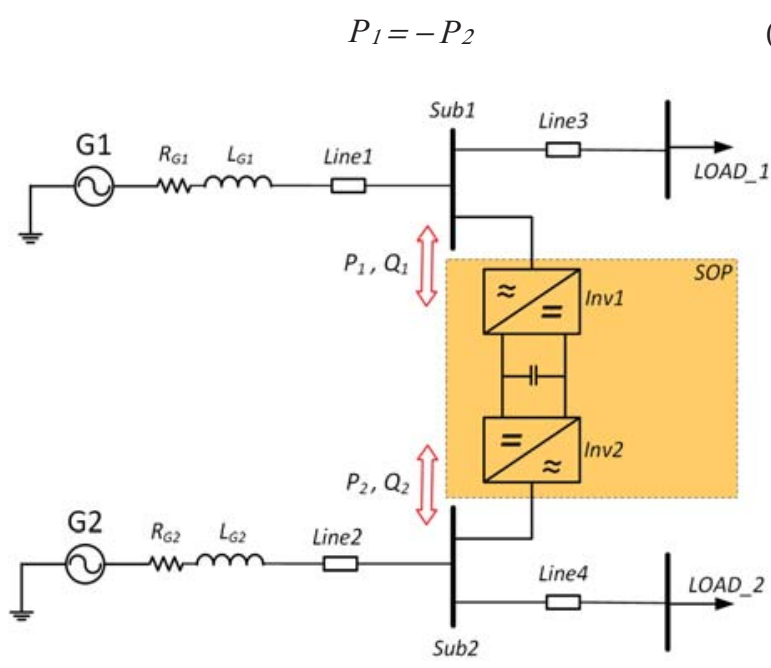

Figure 1. SOP B2B configuration within a distribution network

\section{B. Operating Principles}

The original idea of SOP is developed to give services during normal operation of the installed network but as any electrical system, the abnormal and fault condition behavior is also very much important from safety and system reliability point of view.

\section{1) Normal mode}

In normal operation mode, SOP can give reactive power support to both sides of connection feeders independently. Each converter can work as harmonic compensation devices, similar to Active Power Filter (APF) [18] depending on connected feeder requirements. Device can participate in Volt/Var control actions (i.e. voltage level management by reactive power control) as well [19] within microgrid or smart grids. All these supports can increase the DG units hosting capacity in the distribution network. The device can control the active power flow in either directions which can again increase the hosting capacity of the network and it can also help to solve congestions on a feeder by supplying part of its load from adjacent feeder(s).

\section{2) Abnormal mode}

If a fault happens at one side of the SOP connections, the converter can isolate the other side in a very fast and effective way. The device is capable to isolate any voltage and current disturbances in case of fault or abnormal conditions from one side to other side. SOP can be used as post fault supply restoration supplying the healthy part of the network from one side to another side. These operation modes are discussed in [10], [20] and will not covered by this work.

\section{Communication requirements}

Communication is an essential part of SOP since it needs network information in order to perform right actions or in other words, it needs to receive reference values for active power $\left(P_{r e f}\right)$, reactive power $\left(Q_{r e f}\right)$ or any other services from system operator and higher level controller. With communication link and higher level centralized/decentralized controller, the functionalities and performance of the SOP could be increased substantially. However, this paper will focus only on autonomous control solutions without communication which are also needed as a back-up solution for SOPs which control is based on communication. More advanced and optimal (from local distribution network and DSO point of view) control strategies with high-speed communication (e.g. wireless $5 \mathrm{G}$ ) and as part of whole distribution network management concept will be considered in future studies.

\section{SOP CONTROL}

This section presents controller design for the converters and also reactive power reference generation.

\section{A. Converter control schemes}

The controller design has been discussed in [10] for an average model. This work develops a detail model and further discusses the converters controller in normal (grid connected) operation mode. During normal operation mode (grid connected), both converters are working as current source 
therefore, the inverter controller requires current references from outer control loop. Outer power control schemes are shown in Fig. 2.

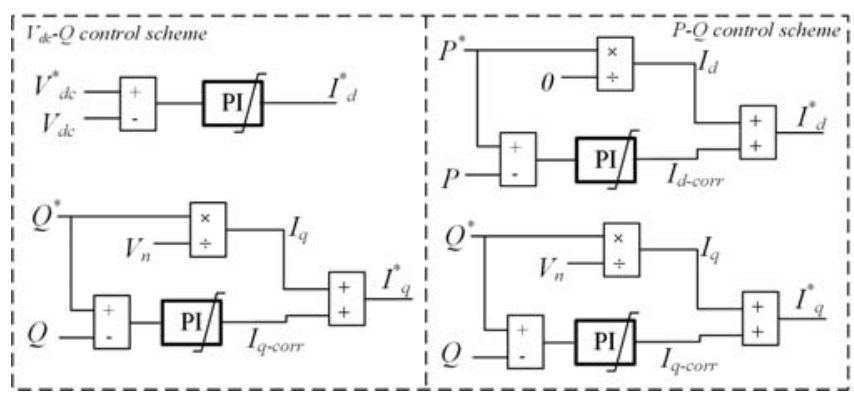

Figure 2. SOP outer power control schemes

One of converters should work in $V_{d c}-Q$ control mode in order to guarantee DC bus voltage regulation. Indeed the other converter can work in $P-Q$ control scheme. There is no need to switch control schemes among converters. Changing the polarity of active power reference $\left(P^{*}\right)$ will change the active power flow direction and the reactive power control loop is equally the same in both control schemes.

For DC bus voltage control, a PI controller is used where its output is considered as $d$ component of reference current, to be followed by inverter. $q$ component of reference current is generated by dividing the reactive power request to the system nominal voltage or it can be only requested reactive power in per unit. A slow PI controller (can have only integral part) is used in parallel to the calculation loop in order to compensate filters reactive power and fine tune the control action. The summation has been considered as $q$ component of reference current, fed to the inverter current controller. Same idea has been used for active power control loop in $P$ - $Q$ scheme.

Inverters inner current control loop is shown in Fig. 3. Here both $d$ and $q$ components are controlled with separate PI controllers. In case of $d$ component loop $\left(v^{c} d\right)$, the PI output is added to $V_{d}$ feedforward and it is subtracted to flux linkage term $\left(I_{q} \omega L\right)$. Instead, in $q$ component loop, the flux linkage term $\left(I_{d} \omega L\right)$ is added to the PI controller output to form $q$ component of control voltage $\left(v_{q}^{c}\right)$.

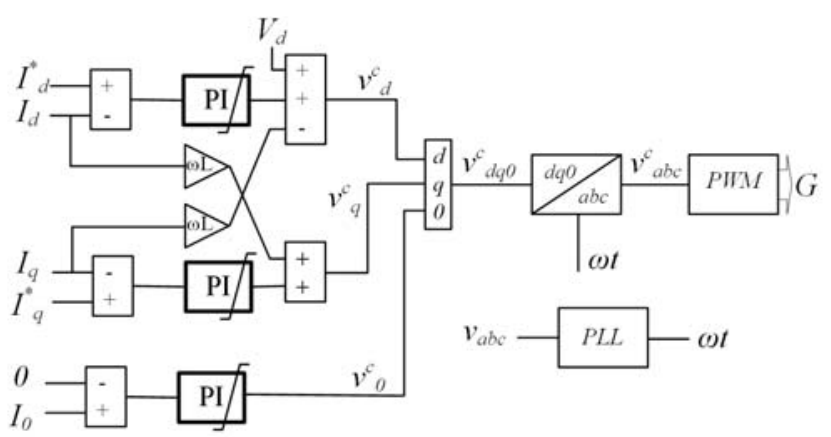

Figure 3. SOP inverters inner current control loop

In B2B configuration, at least one of converters should have zero component controller included in order to set the zero component to null. Without this zero component controller, even very small impedance difference between two sides, will introduce a DC offset or fluctuations to the injected current. Effect of this control loop is shown and discussed at section IV. Finally, the $d q 0$ frame control voltage $\left(v^{c} d q 0\right)$ is transformed to $a b c$ frame which can be fed to PWM block to generate gate signals for switching devices.

\section{B. Autonomous Volt/Var droop scheme}

This paper proposes an autonomous Volt/Var droop control scheme in order to generate reactive power references for the SOP converters according to voltage measurements at SOP connection points. This Volt/Var control loop is shown in Fig. 4. This control is also identical for both sides converters since the reactive power control is decoupled and each converters can work independent to each other as far as those respect to their own rated power.

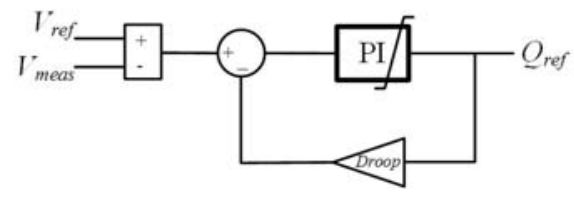

Figure 4. Autonomous Volt/Var droop control loop

The error between measured voltage at connection point and the reference voltage value (here it is considered 1p.u.) is sent to a PI controller. The droop value is used as negative feedback gain as shown in Fig. 4. The droop gain of the regulator is set to $0.06 \mathrm{pu}(6 \%)$ per $1 \mathrm{MVar}$ [21]. This is a design parameter which depends on installed network parameters and designed SOP rated power. In this work the designed system is able to compensate maximum of $\pm 6 \%$ voltage drifts. In the presence of active power loop, the rated power check should be preformed before feeding the reference values to the SOP inverters controllers so that nominal $S$ (VA) should not be exceeded.

$$
\sqrt{P^{2}+Q^{2}}=S
$$

Fig. 5 shows this droop characteristic which has been used in this work. In order to avoid oscillation and instability issues $\mathrm{a} \pm 1 \%$ margin has been considered in order to enable/disable the droop control loop as it has been illustrated in Fig. 5.

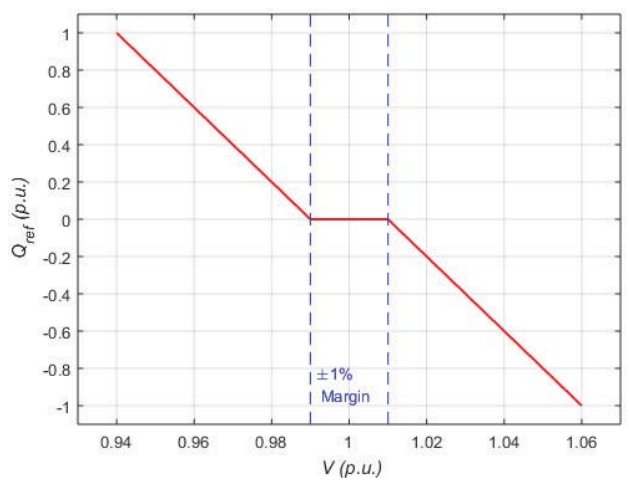

Figure 5. Volt/Var droop characterestic 


\section{Simulation Results}

Fig. 1 network has been used as an example power circuit for simulation study. Matlab sim_power_systems toolbox is used to simulate the example network and SOP power electronics device. TABLE I. reports the simulated power circuit system parameters and TABLE II. reports PI section line parameters.

TABLE I. SIMULATION SYSTEM POWER CIRCUIT PARAMETERS

\begin{tabular}{cc}
\hline \hline G1, G2 & 20kV, 10MVA \\
$\mathrm{R}_{\mathrm{G} 1,2}, \mathrm{~L}_{\mathrm{G} 1,2}$ & $4 \Omega, 0.106 \mathrm{H}$ \\
Line1 & PI section, 10km \\
Line2 & PI section, 4.5km \\
Line3 & PI section, 4.5km \\
Line4 & PI section, 10km \\
LOAD_1 & $5 \mathrm{MW}+0.5 \mathrm{Mvar}$ \\
LOAD_2 & $6 \mathrm{MW}+0.8 \mathrm{Mvar}$ \\
\hline \hline
\end{tabular}

\begin{tabular}{rc} 
TABLE II. & PI SECTION LINE PARAMETERS \\
\hline \hline $\mathrm{R}_{+}, \mathrm{R}_{0}$ & $0.01153,0.01153 \Omega / \mathrm{km}$ \\
$\mathrm{L}_{+}, \mathrm{L}_{0}$ & $1.05 \mathrm{e}-3,3.32 \mathrm{e}-3 \mathrm{H} / \mathrm{km}$ \\
$\mathrm{C}_{+}, \mathrm{C}_{0}$ & $11.33 \mathrm{e}-9,5.01 \mathrm{e}-9 \mathrm{~F} / \mathrm{km}$ \\
\hline \hline
\end{tabular}

Simulated power circuit is a typical radial distribution network. Grid one $(G 1)$ and Grid $2(G 2)$ can be supplied from same substation but here those have been simulated separately in order to simulate independent voltage variations at Subl and $\mathrm{Sub2}$.

SOP has been designed with 1MVA rated power $(10 \%$ of system nominal power). It has been installed between $S u b 1$ and Sub2. SOP parameters have been reported in TABLE III. Both detailed and average models have been simulated for different purposes. A transformer with Y-Y connection has been used as grid coupling interface. The Transformer turn ratio is design $1: 10(20 \mathrm{kV}$ to $2 \mathrm{kV})$ and power electronics devices are connected at low voltage side $(2 \mathrm{kV})$.

TABLE III. SOP SYSTEM PARAMETERS

\begin{tabular}{cc}
\hline \hline Rated power & $1 \mathrm{MVA}$ \\
Coupling Transformer turn ratio & $1: 10$ \\
Coupling Inductance & $5 \mathrm{mH}$ \\
DC bus capacitor bank & $7000 \mu \mathrm{F}$ \\
DC bus voltage set value & $4 \mathrm{kV}$ \\
Passive RC filter & $2 \Omega, 100 \mu \mathrm{F}$ \\
Detailed model switching frequency & $5 \mathrm{kHz}$ \\
Detailed model sampling frequency & $200 \mathrm{kHz}$ \\
Average model sampling frequency & $10 \mathrm{kHz}$ \\
\hline \hline
\end{tabular}

\section{A. Converter control considerations}

In order to evaluate SOP inverters inner current control loop (Fig. 3), detailed simulation model has been used. $P$ and $Q$ reference values have been changed stepwise and the performance of control loop has been observed.

The overall performance of the control loop has been reported in [10], but mostly the average model results are reported. Here detailed model is developed and the performance of the control loop is examined thoroughly. $d$ and $q$ components manage active and reactive powers respectively. Instead, the zero component control loop guarantees balanced and symmetrical there-phase currents. This paper focus is on zero component controller. Without zero component controller, the SOP inverters currents have dc offset and start to deviate from zero reference. This zero component controller is essential for detailed model and consequently for practical final device development. The effect of this control loop is demonstrated here. The simulation results are shown without and then with this zero component control loop to demonstrate the phenomenon and its solution.

Inverter one (Invl) is working in $V_{d c^{-}} Q$ control scheme mode. $V_{d c}$ reference is $4 \mathrm{kV}$ and the reactive power request initially is zero and it has an stepwise change at $\mathrm{t}=0.5 \mathrm{~s}, Q_{\text {ref }}=$ -0.5 p.u.. Inverter two (Inv2) is working in $P-Q$ control scheme mode. Active and reactive power requests are set to zero initially and those have step changes at $\mathrm{t}=1 \mathrm{~s} P_{\text {ref }}=$ 0.4 p.u. and $\mathrm{t}=0.5 \mathrm{~s}, Q_{\text {ref }}=0.4$ p.u. respectively. Grid voltages at both side substations (Sub1 and Sub2) are set to nominal values. Simulation results without including the zero component control loop are shown in Fig. 6. It can be noticed that without any control on zero component, the injected three-phase current starts to deviate from zero dc offset. This effect is due to impedance mismatch between two ac side connections. In a real practical setup, it is quite impossible to have exactly same impedance at both sides.

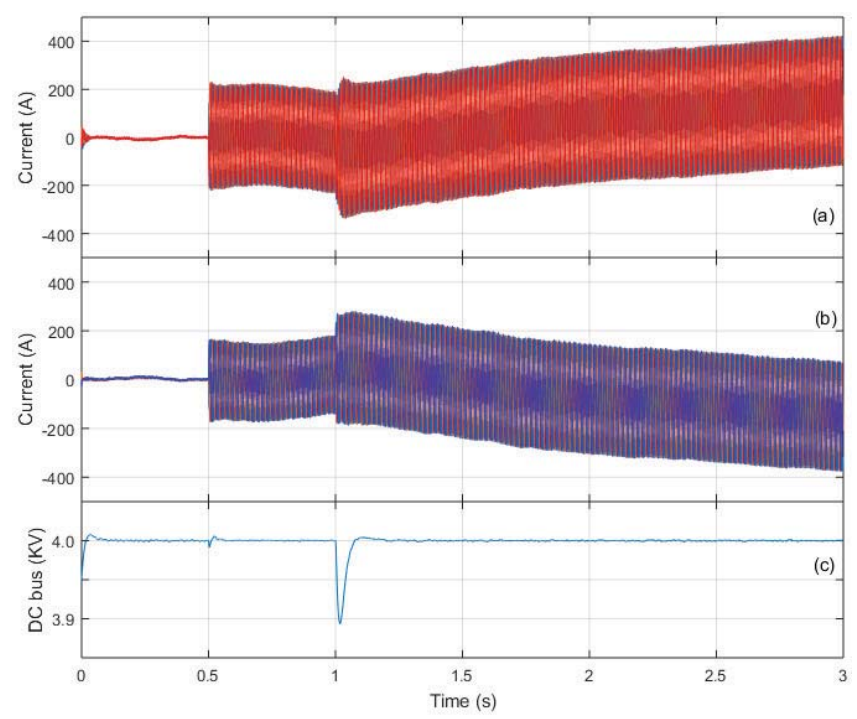

Figure 6. Simulation results without zero component controller (a) Inv1 three-phase currents, (b) Inv2 three-phase currents (c) DC bus voltage 
Zero component controller is an effective solution for this issue. Investigation revealed that adding the zero component control loop to only one of SOP's inverter controller would solve this problem and there is no need to add zero component controller to both inverters control. Fig. 7 demonstrates simulation study results adding this zero component controller to Inv1 control loop only. As it can be seen, this control loop has solved the current deviation issues effectively. Inversely, if the zero component control loop is added to Inv2 control, results are equally the same as Fig. 7.

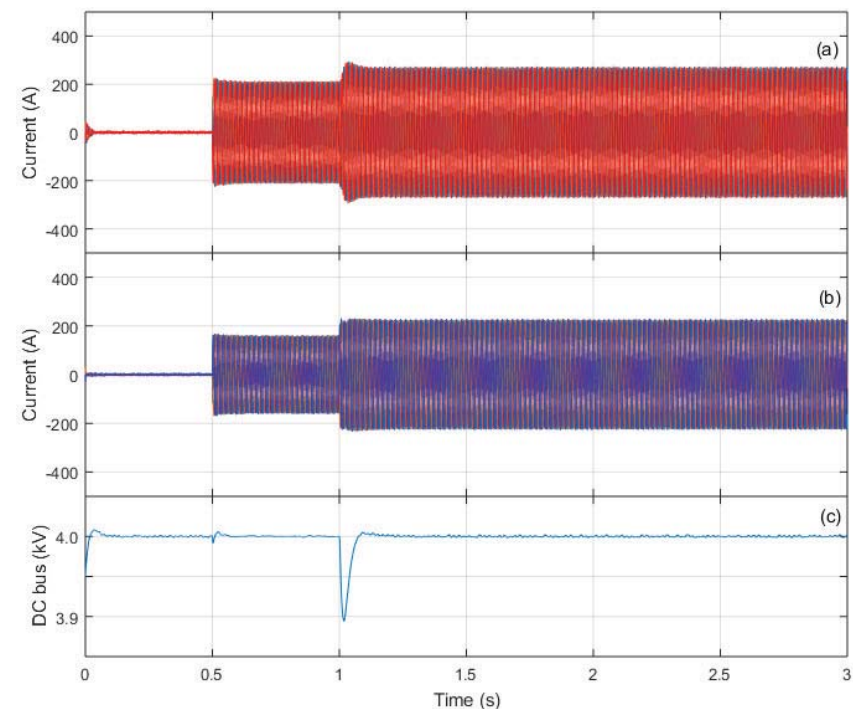

Figure 7. Simulation results with zero component controller (a) Inv1 threephase currents, (b) Inv2 three-phase currents (c) DC bus voltage

DC bus response has been shown for both case simulations without and with zero component controller, Fig. 6(c) and Fig. 7(c) respectively. It can be noticed that zero component controller has almost no effect on DC bus voltage controller. This statement is valid for active and reactive power control performance as well. This is due to the fact that, zero component has no effect on $d$ and $q$ components which are responsible for active and reactive power control.

\section{B. Outer Volt/Var droop performance}

Average model with larger time steps has been used to study the proposed Volt/Var droop controller performance. Fig. 8 shows the simulated voltage profiles at Sub1 and Sub2 without SOP operation. For Subl, initially the voltage is about nominal value. At $\mathrm{t}=2.5 \mathrm{~s}, 5 \%$ voltage drop is simulated which lasts until $\mathrm{t}=5 \mathrm{~s}$ when the terminal voltage came back to its healthy condition. About $6 \%$ voltage rise has been simulated at $\mathrm{t}=7 \mathrm{~s}$ and it lasts till end of simulation. For Sub2, different scenario, first voltage rise and then voltage drop at different moments have been simulated as it can be seen in Fig. 8(b). This differences will show how SOP inverters are able to inject reactive power independently from each others. The active power reference is always set to zero during this simulation study however, DC bus voltage controller is in loop since it is essential for SOP proper functioning.

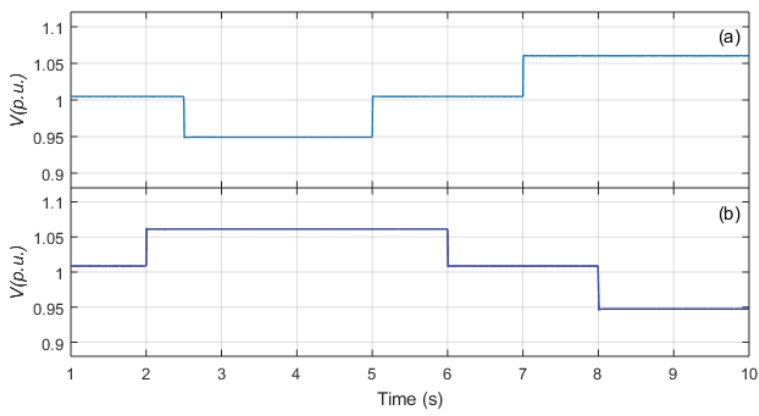

Figure 8. Voltage profiles without SOP operation (a) at $\operatorname{Sub1}$ (b) at $\operatorname{Sub2}$

Fig. 9 shows the terminal voltages with SOP operation. It illustrates how the proposed Volt/Var controller responses to the voltage variations at Sub1 and Sub2. The SOP effectively suppress the voltage variations at both terminals since the voltage variations are within $\pm 6 \%$ range, Fig. 9(a) and (c). There is about $0.5 \mathrm{~s}$ transient time due to Volt/Var droop setting. Although this transient time is okay for voltage drift compensation but it can be reduced by adjusting controller setting. It should be noted that simulated stepwise voltage variation is also the worst case scenario since in distribution system, this kind of voltage drifts usually happen slowly.

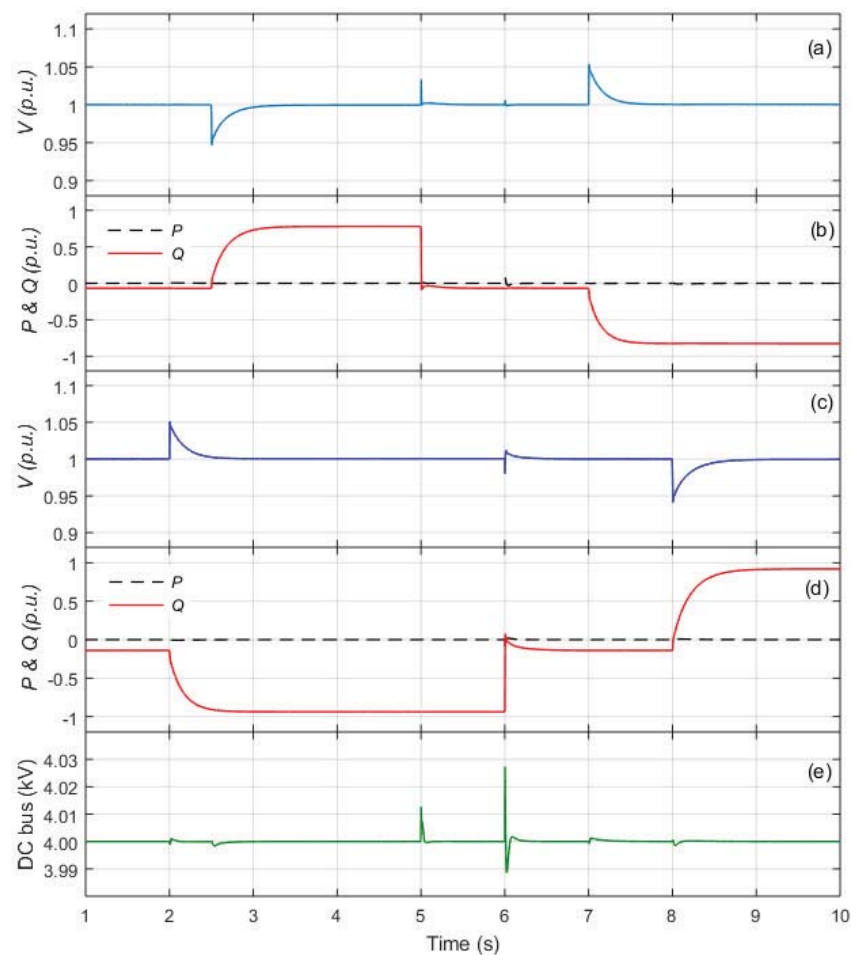

Figure 9. SOP performance to mitigate voltage drifts (a) voltage at Subl, (b) active and reactive power of $I n v 1$, (c) voltage at $S u b 2$, (d) active and reactive power of Inv2, (e) SOP DC bus voltage

Fig. 9(b) shows how SOP Inv1 reacts to voltage variation. The SOP is in operation starting the simulation where SOP Invl absorbs some amount of reactive power (negative) in order to regulate the voltage at rated value. At $\mathrm{t}=2.5 \mathrm{~s}$ it starts to inject reactive power to compensate $5 \%$ voltage drop. At $\mathrm{t}=5 \mathrm{~s}$ the reactive power set value came back to its initial value 
by removing voltage drop at $S u b 1$ terminal. There is a small variation on $\mathrm{DC}$ bus voltage due to fast reactive power removal Fig. 9(e). At $\mathrm{t}=7 \mathrm{~s}$, about $5 \%$ overvoltage is simulated so the SOP Invl starts to absorb reactive power and it compensates the over voltage drift effectively. Fig. 9(d) shows SOP Inv2 active and reactive power responses. Similarly, Inv2 absorbs reactive power within period $t=[2-6] \mathrm{s}$ and injects reactive power at $\mathrm{t}=[8-10] \mathrm{s}$ in order to deal with over voltage and voltage drop drifts respectively. Outside these periods, it absorbs about 0.1 p.u. reactive power and compensates slight over voltage at $S u b 2$, as it is depicted in Fig. 8(b) also. DC bus voltage profile is also shown in Fig. 9(e). With each transient at both side terminals and when the SOP inverters change their reactive power set points, DC bus experiences small amount of increase or decrease. DC bus voltage controller performs well to keep DC bus voltage always around reference value $(4 \mathrm{kV})$.

\section{CONCLUSION REMARKS AND FUTURE WORKS}

Active and reactive power control needs locally in distribution networks as well as between DSO and TSO networks will increase in the future due to connection of large amount of renewable generation and EVs. SOPs could improve DG hosting capacity (congestion management) and voltage control of future distribution networks. Also investments on increasing MV feeder line capacities could be avoided. In addition, the active management of SOPs as part of the ANM scheme could decrease potential restrictions in DSO network connected flexibilities possibility to provide system-wide i.e. TSO level technical services. SOPs could also provide interesting possibility in the future for more optimized and efficient integration of e.g. battery energy storages and fast EV charging stations by coupling of $\mathrm{AC}$ and DC networks.

This paper presents simulation study on SOP as a promising power electronics solution for distribution network applicable within modern smart grid systems. Detailed model has been developed and practical controller for reference current generation and also inverters control have been designed. The controllers' performance have been verified through Matlab based simulation. As a higher level (outer) control solution, an autonomous Volt/Var droop control loop has been proposed so the SOP can work in stand-alone manner. In principle, system wide communication would give better performance and can optimize operation performance of SOP. However, proposed communication-less control mode can also be used as an alternative, back-up or in combination with communication based solutions. Within this work, only reactive power support by SOP has been studied. Future work and research studies can be performed for active power flow control algorithms which can work in parallel with reactive power controller.

\section{REFERENCES}

[1] F. Capitanescu, L. F. Ochoa, H. Margossian, and N. D. Hatziargyriou, "Assessing the potential of network reconfiguration to improve distributed generation hosting capacity in active distribution systems," IEEE Trans. Power Syst., vol. 30, no. 1, pp. 346-356, 2015.
[2] P. Li, H. Ji, S. Member, C. Wang, and S. Member, "Coordinated Control Method of Voltage and Reactive Power for Active Distribution Networks Based on Soft Open Point," IEEE Transactions Sustain. Energy, vol. 8, no. 4, pp. 1430-1442, 2017.

[3] H. Laaksonen and P. Hovila, "FlexZone Concept to Enable Resilient Distribution Grids - Possibilities in Sundom Smart Grid," in Proc. CIRED 2016 Workshop, 2016.

[4] J. M. Bloemink and T. C. Green, "Increasing distributed generation penetration using soft normally-open points," IEEE PES Gen. Meet. PES 2010, pp. 1-8, 2010.

[5] J. M. Bloemink and T. C. Green, "Benefits of distribution-level power electronics for supporting distributed generation growth," IEEE Trans. Power Deliv., vol. 28, no. 2, pp. 911-919, 2013.

[6] F. Blaabjerg, Z. Chen, and S. B. Kjaer, "Power Electronics as Efficient interface in Dispersed Power Generation Systems in Dispersed Power Generation Systems.," IEEE Trans. Power Electron., vol. 19, no. 5, pp. 1184-1194, 2004.

[7] H. Hafezi, E. Akpinar, and A. Balikci, "Assessment of two different reactive power estimation methods on single phase loads," 2014 16th Int. Power Electron. Motion Control Conf. Expo., no. September, pp. 82-87, 2014.

[8] H. Hafezi and R. Faranda, "Dynamic Voltage Conditioner: A New Concept for Smart Low-Voltage Distribution Systems," IEEE Trans. Power Electron., vol. 33, no. 9, pp. 7582-7590, 2018.

[9] H. Hafezi and R. Faranda, "Open UPQC series and shunt units cooperation within Smart LV Grid," 2017 6th Int. Conf. Clean Electr. Power Renew. Energy Resour. Impact, ICCEP 2017, pp. 304-310, 2017.

[10] W. Cao, J. Wu, N. Jenkins, C. Wang, and T. Green, "Operating principle of Soft Open Points for electrical distribution network operation," Appl. Energy, vol. 164, pp. 245-257, 2016.

[11] C. Wang, G. Song, P. Li, H. Ji, J. Zhao, and J. Wu, "Optimal siting and sizing of soft open points in active electrical distribution networks," Appl. Energy, vol. 189, pp. 301-309, 2017.

[12] H. Ji, C. Wang, P. Li, F. Ding, and J. Wu, "Robust Operation of Soft Open Points in Active Distribution Networks with High Penetration of Photovoltaic Integration," IEEE Trans. Sustain. Energy, vol. 3029, no. c, 2018.

[13] J. M. Bloemink and T. C. Green, "Increasing photovoltaic penetration with local energy storage and soft normally-open points," IEEE Power Energy Soc. Gen. Meet., pp. 1-8, 2011.

[14] J. Flottemesch and M. Rother, "Optimized energy exchange in primary distribution networks with DC links," in 2004 IEEE International Conference on Electric Utility Deregulation, Restructuring and Power Technologies. Proceedings, 2004, no. April, p. 108-116 Vol.1.

[15] E. Romero-Ramos, A. Gómez-Expósito, A. Marano-Marcolini, J. M. Maza-Ortega, and J. L. Martinez-Ramos, "Assessing the loadability of active distribution networks in the presence of DC controllable links," IET Gener. Transm. Distrib., vol. 5, no. 11, p. 1105, 2011.

[16] C. Long, J. Wu, L. Thomas, and N. Jenkins, "Optimal operation of soft open points in medium voltage electrical distribution networks with distributed generation," Appl. Energy, vol. 184, pp. 427-437, 2016.

[17] N. Okada, M. Takasaki, H. Sakai, and S. Katoh, "Development of a 6.6 kV - 1 MVA transformerless loop balance controller," PESC Rec. IEEE Annu. Power Electron. Spec. Conf., vol. 2, pp. 1087-1091, 2007.

[18] H. Vahedi, A. A. Shojaei, L. A. Dessaint, and K. Al-Haddad, "Reduced DC-Link Voltage Active Power Filter Using Modified PUC5 Converter," IEEE Trans. Power Electron., vol. 33, no. 2, pp. 943-947, 2018.

[19] K. Sirviö, L. Välkkilä, H. Laaksonen, K. Kauhaniemi, and A. Rajala, "Prospects and Costs for Reactive Power Control in Sundom Smart Grid," in 2018 IEEE PES Innovative Smart Grid Technologies Conference Europe (ISGT-Europe), 2018, pp. 5-10.

[20] A. Aithal, G. Li, J. Wu, and J. Yu, "Performance of an electrical distribution network with Soft Open Point during a grid side AC fault," Appl. Energy, no. August, pp. 0-1, 2017.

[21] P. Giroux, G. Sybille, and H. Le-Huy, "Modeling and Simulation of a distribution STATCOM using Simulink's Power System Blockset" in IECONOl: The 27th Annual Conference of the IEEE Industrial Electronics Society, 2001, pp. 990-994. 